\title{
Benchmarking as a Determinant of Modern Mining Education
}

\author{
Alena Chupryakova ${ }^{I^{*}}$, Lyudmila Zakonnova ${ }^{1}$, and Mariana Petrova $^{2}$ \\ ${ }^{1}$ T.F. Gorbachev Kuzbass State Technical University, Belovo Branch, $6526446 б$ Ilyica st. \\ 32, Belovo, Russia \\ ${ }^{2}$ Vistula Academy of Finance and Business in Warsaw, 3 Stokłosy Str., 02-787 Warsaw, \\ Poland
}

\begin{abstract}
This paper discusses the adaptation of mining education to the modern requirements of improving the management of mining enterprises. The authors substantiate the necessity and expediency of including a separate benchmarking course in the programs of university and postgraduate mountain education, which is based on the postulates of the process approach to management. It is necessary to gain understanding and knowledge of all processes occurring in the organization, based on illustrating the flow of processes with drawings, graphs of changes in process parameters; have a clear understanding of the standards in order to use their experience in relation to their activities, as well as managers should have a pronounced desire to improve their activities in order to achieve the maximum financial result. The paper presents the results of a study on testing the mechanism for using benchmarking tools conducted by the authors at mining enterprises of an open and underground mining method. Among the main tasks of top managers to reduce the risks of inadequate business processes in coal enterprises, it is necessary to resort to a criterion-based assessment of business processes through internal process benchmarking and the provision of analytical information to interested parties, which will allow them to identify «narrow» places during the implementation of the process and make informed management decisions. The presented conclusions are recommended for consideration when drawing up educational standards and programs for the training and retraining of managerial personnel for the mining industry.
\end{abstract}

\section{Introduction}

In the past few years, in the theory and practice of mining management, the problem of identifying the determinants of mining education has gained new significance due to the emphasis on the innovativeness of managerial thought in terms of increasing the efficiency of resource consumption, improving the organization of labor, production and management of the industry, holdings and individual mining enterprises. [1-3] Therefore, in these conditions, when forming the curriculum of university and postgraduate mining education systems, among the various approaches to the management of mining enterprises, the process approach and its specific tool, benchmarking, which has its own characteristics and advantages, should be emphasized [4-7].

\footnotetext{
${ }^{*}$ Corresponding author: chupa.69@mail.ru
} 
Of course, one should not deny the importance of a systematic approach to management, which involves considering the mining enterprise as a whole and its structural divisions as separate open production and economic systems. In addition, in training programs, plans, as well as in the organization of research activities, due attention should be paid to studying for subsequent effective application at specific mining enterprises:

- a system-component approach, which allows to highlight new qualitative features of elements and subsystems of large industrial-economic systems of a holding type;

- a system-structural approach that explores the optimality of internal connections and interactions of elements and subsystems of the general system, the structural properties of which are largely determined by the nature and stability of these relationships;

- a system-functional approach that emphasizes the integrated result of functional dependencies not only between internal elements and subsystems, but also between the system itself and the super-system (external environment), which does not exclude building a hierarchical sequence in coordinating and coordinating management decisions with a subcoordinating component in the process of their adoption.

\section{Materials and methods}

It should also indicate the importance of the situational approach for management, the methodology of which implies the justification of the possibility of adapting a particular mining enterprise to the changing market conditions of mining equipment markets, vehicles, markets of fuel and energy resources in which this enterprise is a player. That is, it is the application of the situational approach in management that allows us to achieve the strategic goals of the development of a mining enterprise in deterministic conditions, conditions of uncertainty and risk.

Dwelling in more detail on the process approach, it should be said about its advantage, based on the fact that the entire activity of the mining enterprise, aimed at obtaining the final result, becomes a single object of management. Consequently, the conclusion suggests itself that the larger the mining enterprise and the processes occurring in this complex system, the more clearly the advantages of the process approach. Conversely, the more detailed the processes are fragmented, the more the benefits of this approach are minimized. In this case, one should be guided by the thesis about the desire to get rid of local optimization and proceed from the fact that the management of any production and economic system is aimed at the effective achievement of the desired results with a given accuracy, which should be mastered by training managers in the system of university and postgraduate mining education. At the same time, one should clearly understand the effect of one of the fundamental principles of the process approach, which states that each business process in a mining enterprise has a person responsible for its functioning and results.

A business process is a chain of logically related, repetitive actions that result in the use of enterprise resources to process an object (physically or virtually) in order to achieve certain measurable results or products to satisfy internal or external consumers [8].

Modern mining enterprises are characterized by complex business processes, a complex structure, sustainable production relationships. Therefore, the organization of the process approach in the company will affect the management efficiency and effectiveness of the company. Guided by this fact, when developing educational programs for the training and retraining of managerial personnel for the mining industry, it is necessary to include a benchmarking course in them.

The development of the concept of quality management (Total Quality Management TQM) today has led to a common vision of its effectiveness in most mining enterprises. In addition, domestic enterprises of different industry sectors and different forms of ownership today, entering into informal relations with partners or competitors, often adopt their 
experience and achievements, that is, they use benchmarking as a management tool, but they do not use the term. At the same time, it is a mistake to think that this is a one-time action; one should proceed from its systemic nature.

In support of the feasibility of including a benchmarking course in educational programs, it should be noted that there are already developments on the use of different types of benchmarking [9].

So internal benchmarking is the simplest type of benchmarking (identifying and inheriting the best practices of structural units of one enterprise in order to increase its own performance), as it is carried out within the framework of one company. Functional departments of the organization and a group of companies included in the holding can be subjected to internal benchmarking.

Speaking about external benchmarking and its effectiveness, we should proceed from the fact that in the typology of this type there are:

-competitive benchmarking, which is mainly aimed at the implementation of preventive measures in the competition, providing a competitive advantage in gaining time;

- general benchmarking, which in content has similar characteristics to competitive, but comparison is made with industry or market leaders and orientation to their high achievements;

- functional benchmarking, which involves comparing the effectiveness of certain similar functions that take place in almost any mining enterprise (mine, mine, processing plant) according to certain criteria.

Of particular interest is the classification of benchmarking depending on the objects of comparison, according to which there are:

- strategic benchmarking involves the possibility of comparing different options for strategic alternatives, which can be viewed through the prism of multi-scenario modeling of the development of the organization. Its features should be known to senior managers who already have a vision in the field of risk management and other global categories. Therefore, in conditions of multilevel education, it is logical to give this theoretical block of the benchmarking course to the appropriate students of the educational program;

- process benchmarking involves a description of the business processes of a particular organization using situational analysis techniques, the basic rules of quality management and comparison with the reference model. You can take the industry leader organization as a reference, having processes similar in their characteristics to those carried out at the enterprise in question, with a view to their possible copying;

- benchmarking of indicators is applied as part of the implementation of such a principle of the process approach, which involves highlighting in the description of each business process some key indicators that reflect either the course of the process, or the result, or the effect on the overall functioning of a complex system.

\section{Results and discussion}

Benchmarking of processes and indicators should be included in the educational programs of mining universities, and a clear understanding of the division of processes into basic, auxiliary, maintenance and management.

A study conducted by the authors on the typologization of processes carried out at mining enterprises, classified by type of mining as open and underground, showed that with the underground method of coal mining, the main processes should include:

- the process of preparing reserves, including such types of work as sinking, in which usually the preparatory work and production sites are involved); blasting; drilling (both processes require the participation of blasting sites and explosive storage facilities). The product of this process should be considered the amount of penetration, the volume of prepared reserves; 
- the process of installation / dismantling of underground mining equipment;

- the mining process carried out by the mining sites, the product of which should be considered ordinary coal;

- the process of mine transport of coal and rock to the surface;

- the process of transporting coal and rock to the warehouse, carried out by technological vehicles;

- the sorting and beneficiation process, which involves integrated coal processing sites. The product of this process should be considered coal enriched;

- the process of production of coal mixtures;

- the storage process, in which a section of special equipment is involved in bulldozer work;

- the process of delivery to the departure station, including loading operations;

- delivery process to the consumer / buyer.

With the open method of coal mining, we consider such processes as the main ones:

- stockpile preparation process, including:

1. motorized overburden (namely, excavation for motor vehicles, over-excavation, blasting, drilling, bulldozer transportation by technological transport);

2. transportless overburden (with similar types of work);

3. railway overburden (with similar types of work);

4. transport dumping overburden (with similar types of work);

- the production process, including excavation at production, bulldozer operations, blasting, drilling, etc.);

- the process of reclamation, involving planning decisions, bulldozer work, bioremediation, etc.);

- the process of transporting coal and rock to the warehouse;

- the sorting and beneficiation process, which involves integrated coal processing sites. The product of this process should be considered coal enriched;

- the process of production of coal mixtures;

- the storage process, in which a section of special equipment is involved in bulldozer work;

- the process of delivery to the departure station, including loading operations;

- delivery process to the consumer / buyer.

Due to the similarity of the names of the processes, there may be an erroneous opinion that they should be described in the same way, however, this is not so.

At the same time, it should be understood that self-analysis of the processes of a mining enterprise includes an assessment of the level of implementation of the goals of each process, as well as an assessment of performance indicators. Setting goals within each process is carried out by decomposing the goals of the parent coal enterprise at the level of each process.

A specific feature of the activities of mining enterprises is their integrated structure. About $75-80 \%$ of coal production in our country is controlled by only twelve large companies, including not only coal mining corporations, but also metallurgical and steel holdings. And this fact necessitates the formation of the goals of mining enterprises taking into account the strategic goals of the integrated group, as well as subsidiaries included in the holding, taking into account the goals of the production unit.

To assess the course and effectiveness of business processes, it is advisable to develop a system of key criteria. In the mentioned study, we proposed the following as key criteria for the effectiveness of the processes:

- process quality;

- the cost of the process;

- process safety;

- compliance of the process with legal standards.

The criteria-based algorithm for evaluating business processes as part of the process benchmarking provided that each criterion had 2-3 quantitative indicators. 
In the general case, step-by-step instructions for using the benchmarking tool were proposed, which should guide any mining enterprise, provided that among the employees there are specialists trained in special programs in the field of benchmarking:

Step One - Situational self-assessment of the enterprise and identification of areas for improvement (you can use SWOT analysis, STEP / PEST analysis and other techniques at this step).

Step Two - Description of the benchmark for comparison.

Step Three - Development of key evaluation criteria and quantitative parameters (indicators) of the evaluation.

Fourth step - Finding a reference enterprise and choosing the form of a benchmark comparison.

Step Five - Collection of information suitable for use in a formalized form.

Sixth step - systematization and processing of the collected information, determination of limitations, calculation of assessment indicators

Seventh step - bringing the results of benchmarking and general recommendations to interested parties.

Step Eight - Repeated self-assessment and analysis of improvements.

\section{Conclusion}

Thus, in the course of the study on the use of internal process benchmarking tools in mining enterprises, the object of comparison was the most effective structural unit with similar business processes based on the compiled process maps according to the criteria and indicators proposed by the authors. In this case, the authors proceeded from the fact that it is not advisable to compare the flow of business processes by one criterion, since the high probability of a subjective description will not allow reflecting the whole range of problems and opportunities for managers to improve the activities of a mining enterprise or its separate structural unit. However, according to the results of the criteria-based assessment, the calculation of the integral indicator based on the application of qualimetry methods in the processing of information made it possible to clearly demonstrate the main parameters of each business process and draw general conclusions on the situation at the mining enterprise.

The integrated structure of any large company as a whole and mining holdings in particular has a number of drawbacks, among which it should be noted that the management of a mining holding, which includes many production units, does not receive complete information about the activities of individual mines, sections, concentration plants, service enterprises . And the possession of inferior, that is, not relevant, not timely, not relevant, not complete information affects the inefficient distribution and use of resources, including financial. To reduce these risks, it is necessary to resort to a criterion assessment of business processes through internal process benchmarking and the provision of analytical information to interested parties (owners, volume managers, partners, etc.), which will allow them to identify bottlenecks on the basis of activity process maps during the implementation of the process and make informed management decisions. To implement this task, conclusions based on the results of the study are recommended for consideration in the preparation of educational standards and programs for the training and retraining of managerial personnel for the mining industry.

\section{References}

1. N. Nenkov, Yu. Dyachenko, M Petrova, G. Bondarenko, V. Pustovit, European Journal of Sustainable Development, 6(4), 353-360 (2017) 
2. V. Jarmusevica, D. Ilisko, J. Badjanova, V. Jukss, M. Petrova, Conference 1st-3rd, Palma, Mallorca, Spain, 1, 10449-10454 (2019)

3. I. Linde, M. Petrova, Innovations in Science and Education, 4 303-308 (2018)

4. T. Uteubayev, M. Petrova, I. Lyubenova, Innovations in Science and Education, 4, 491495 (2018)

5. O. Baklanova, M. Petrova, V. Koval, Economic Studies, 29(1), 68-91 (2020)

6. M. Petrova, V. Koval, M. Tepavicharova, A. Zerkal, A. Radchenko, N. Bondarchuk, Journal of Security and Sustainability Issues, 9(3) 897-907 (2020)

7. I. Gryshova, M. Petrova, M. Tepavicharova, A. Diachenko, T. Gutsul, Entrepreneurship and Sustainability Issues 7(1), 690-703 (2019)

8. M. Petrova, M. Tepavicharova, L. Boykova, E3S Web of Conferences, 41 (2018)

9. M. Petrova, M. Tepavicharova, L. Boykova, Bulletin of Ablai Khan KazUIRandWL. Series Ïnternational Relations and Regional Studies", 1(27), 79-86 (2017) 